\title{
The cleaning process model of diesel fuel in an electric field
}

\author{
Alexander Abramov ${ }^{1}$, Alexander Morozov ${ }^{1, *}$, Anastasia Koshkina ${ }^{2}$, Sergey Petryakov ${ }^{1}$ and \\ Julia Nuretdinova ${ }^{3}$ \\ ${ }^{1}$ Federal State Budgetary Educational Institution of Higher Education Ulyanovsk State Agrarian \\ University, Ulyanovsk, Russian Federation \\ ${ }^{2}$ Federal State Budgetary Educational Institution of Higher Education Ulyanovsk State Tecnical \\ University, Ulyanovsk, Russian Federation \\ ${ }^{3}$ Federal State Budgetary Educational Institution of Higher Education Ulyanovsk State University, \\ Ulyanovsk, Russian Federation
}

\begin{abstract}
The authors of the article carried out the analysis of the failure causes of diesel engine types 4Ч 110/125 and 4ЧН 110/125. As a result of this analysis it was found that the highest percentage of failures occurred in the high-pressure fuel pump and nozzle. The procedure of the electric cleaning process of diesel fuel in an electric field is also considered in the article. A mathematical model of the electric cleaning process of diesel fuel in an electric field has been obtained and the boundaries of the initial parameters of the electric field have been determined.
\end{abstract}

\section{Introduction}

It is well known that the least reliable unit of tractors and cars is the engine. The distribution analysis of diesel engine failures of the type 4Ч 110/125 and 4ЧН 110/125 has shown that the components of the fuel supply system have the highest probability of failures [1]. At the same time, engines are high-tech products, as they contain precision pairs, and, therefore, they are costly in restoring their performance and in maintenance (PM).

The output parameters of the fuel equipment directly determine the nature of the working process of a diesel engine, its power, fuel efficiency and reliability in operation. Failures of the components of the fuel system make up an essential part of diesel failures [2]. For instance, in engines of types 4Ч 110/125 and 4ЧН 110/125, the failure rate of the fuel system components is $45 \%$.

The percentage of failures of the fuel supply system components of engine types 44 $110 / 125$ and 4 ЧH 110/125 is shown in fig. 1 . The highest percentage of failures occurs in the high-pressure fuel pump (HPFP) with 35\%, failures of the injection timing device account for $15 \%$ and of the nozzle $-15 \%$.

\footnotetext{
* Corresponding author: alvi.mor@mail.ru
} 


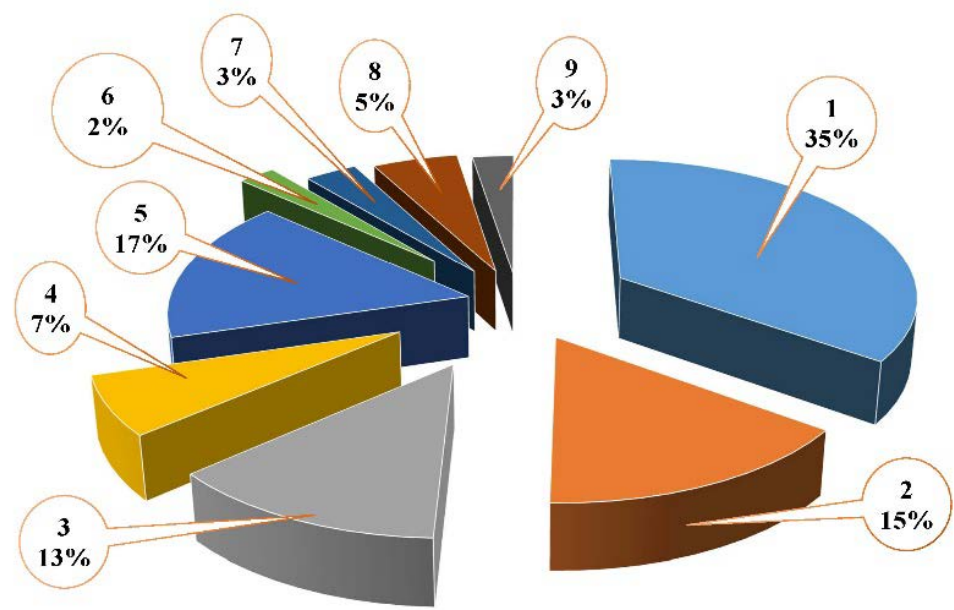

Fig. 1. Failure distribution diagram of engine fuel system components: 1- high pressure fuel pump; 2 - nozzle, 3 - high pressure pipe, 4 - low pressure pipe, 5 - injection timing device, 6 - fuel priming pump, 7 - fuel tank parts, 8 - fine filter, 9 - coarse filter.

It was found that the most probable cause of failures in high pressure fuel pumps and injectors is the use of low-quality fuel - 49\%, fuel of inappropriate seasonal types - $12 \%$, and poor-quality work to restore the efficiency and maintenance of high pressure fuel pumps and nozzles - 29\% (Fig. 2).
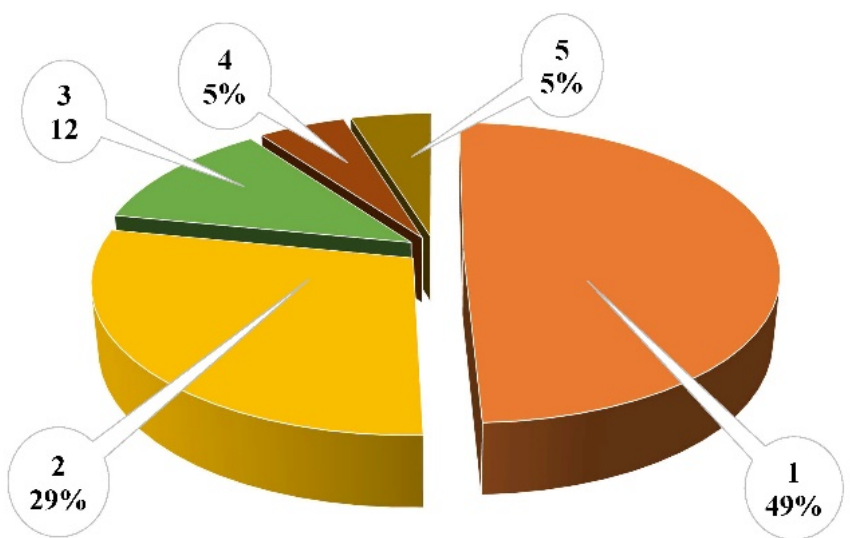

Fig. 2. The causes of failures of the high pressure fuel pump and nozzles: 1- the use of low-quality fuel, 2-poor-quality maintenance work and restoration of performance, 3-the use of fuel which does not correspond to seasonality 4 - the violation of operation modes, 5 - the wear of the fuel system components.

Due to the use of fuel which does not meet the quality requirements, the engines develop an effective power less than the rated one by $12 \ldots 17 \%$, which increases fuel consumption by $12 \ldots 25 \%$, while reducing tractor performance by $12 \ldots 30 \%$ [2].

The use of low-quality fuel contributes to the accelerated wear of high pressure fuel pump components and nozzles [3], as a result of which the geometrical arrangement changes, as a consequence the gaps in the movable and fixed joints increase changing the relative position of the surfaces of the parts and affecting the surface hardness and microgeometry of the surfaces of the parts [4-5]. 


\section{Methodology of Researches}

At present, there are many methods and contrivances to reduce contaminants of both mineral and vegetable origin in diesel fuel [4 - 6]. The most promising of them is the method of electrical cleaning, which allows one to clean the fuel from both mechanical and liquid contaminants.

The goal of this study is to provide a theoretical justification for the method of cleaning diesel fuel in an electric field.

Fig. 3 presents a functional diagram of the proposed method for electric cleaning of diesel fuel in the engine fuel system [7].

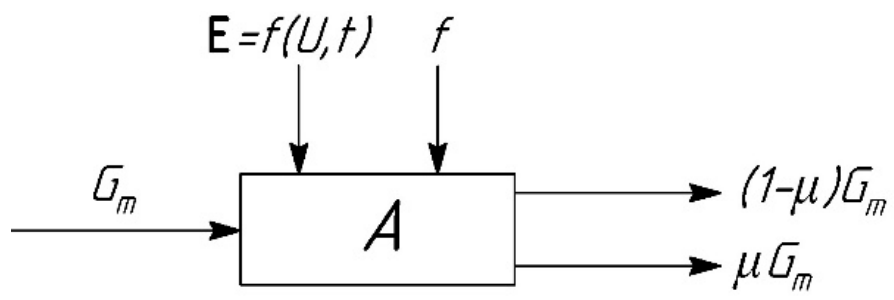

Fig. 3. Functional diagram of the electric cleaning process of diesel fuel in the engine's fuel supply system: $G_{m}$ - hourly fuel consumption, $\mathrm{kg} / \mathrm{s} ; \mathbf{E}$ is the electric field strength, $\mathrm{V} / \mathrm{m} ; U$ is the voltage at the electrodes of the device, $\mathrm{V}$; $t$ is the exposure time of the electric field to diesel fuel until it is completely clean, s; $A$ - the production rate of the device for electrical fuel cleaning $\mathrm{kg} / \mathrm{s} ; \mu$ is the fraction of contaminants in diesel fuel, $\%$; $f$ - disturbing random factors.

Diesel fuel represents a complex dispersed system in the form of a combination of various hydrocarbons, organic and inorganic contaminants, including water and solid abrasive contaminants with wear products of the diesel fuel equipment [8].

The theory of stability and coagulation of dispersed systems offered by DeryaginLandau-Fairway-Overbeck [6] considers aggregative stability as the result of the balance of molecular attraction forces and electrostatic repulsion forces between dispersed particles, which is described by the expression:

$$
I=\frac{16 \pi D a N}{2 \int_{a}^{\infty} \exp \left(\frac{W}{R T}\right) \frac{d S}{S^{2}}},
$$

where: $a$ - the radius of particles, m; $D$ - the coefficient of their diffusion; $N$ - the number of particles; $W$ - energy of particles' interaction, $\mathrm{J} ; R$ - the universal gas constant, $\mathrm{J} /(\mathrm{mol}$ $\mathrm{K}$ ); $T$ - absolute temperature, $\mathrm{K} ; S=\frac{h}{r}$ ( $h$ - the distance between the surfaces of particles, $\mathrm{m} ; r$ - the distance between the centers of particles, $\mathrm{m}$ ).

The bahavior pattern of contaminating particles of diesel fuel under the influence of an electric field is given in fig. 4. 


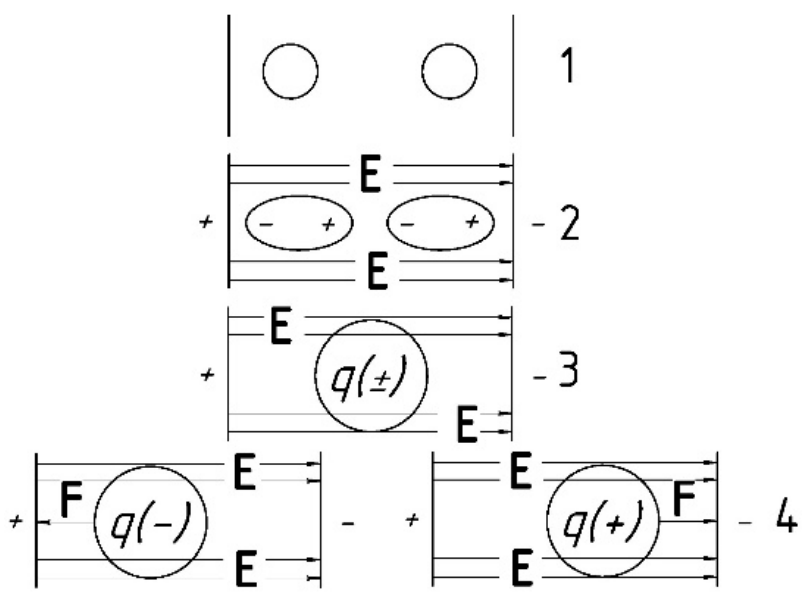

Fig. 4. The behavior pattern of contaminating particles of diesel fuel under the influence of an electric field: $\mathbf{E}$ - electric field strength, V/m; $q$ is the total charge of the coagulated particle, C; $\mathbf{F}$ is the force acting on the coagulated particle from the side of the electric field, $\mathrm{N}$.

The process of coagulation of diesel fuel contaminants, and its result is an increase in particle size regardless of their nature, can be explained as follows: under the influence of an electric field, their energy barrier decreases so that all particles easily overcome it, as a result, all particle collisions will be effective, which will lead to their sticking together. With respect to liquid dielectric media, it is necessary to meet the conditions for its sufficiently low dispersion, when phenomena at the phase boundary can be neglected.

The interaction of contaminating particles with radii $a_{1}$ and $a_{2}$ located at a distance $r>>a$ from each other in an unlimited uniform electric field with strength $E$ is shown in fig. $5 a$.

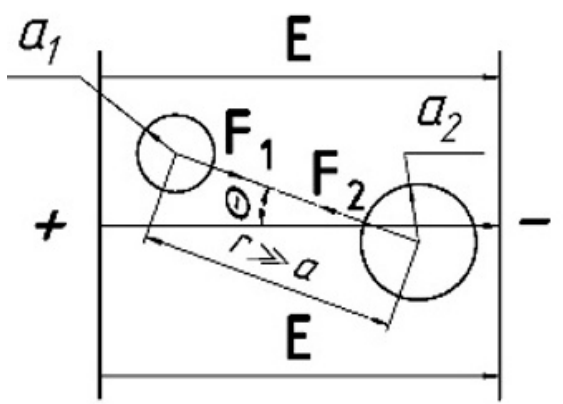

$a$

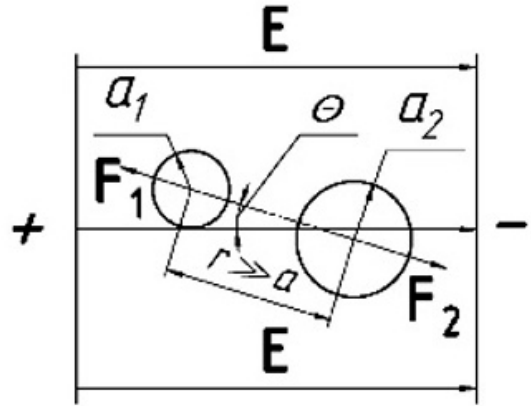

$b$

Fig 5. The interaction of contaminating particles in an electric field: $a$-particles move towards one another and coagulate; $b$-particles move one from another to the electrodes of analogous poles.

The system of forces acting on contaminating particles with radii $a_{1}$ and $a_{2}$ in a uniform electric field can be presented in the following way:

$$
\mathbf{F}_{\mathbf{1}}=\frac{3 a_{1}^{2} a_{2}^{3} K^{2} \mathbf{E}^{2}}{r^{4}}\left[2\left(1+\frac{2 a_{1}^{3} K}{r^{3}}\right) \cos ^{2} \theta-\left(1-\frac{2 a_{1}^{3}}{r^{3}}\right) \sin ^{2} \theta\right],
$$




$$
\mathbf{F}_{2}=\frac{3 a_{1}^{2} a_{2}^{3} K^{2} \mathbf{E}^{2}}{r^{4}}\left(2+\frac{2 a_{1}^{3} K}{r^{3}} \sin \theta \cdot \cos \theta\right)
$$

where: $\mathbf{F}_{1}$ и $\mathbf{F}_{2}$ - the forces acting on particles in a uniform electric field, $\mathrm{N} ; \boldsymbol{\theta}$ - the angle between the direction of the field and the line connecting the centers of particles; $K$ - the parameter determining the dispersion of the medium or its structure characteristics, $K=\frac{\varepsilon_{a}-\varepsilon_{i}}{\varepsilon_{a}+2 \varepsilon_{i}} \sqrt{\varepsilon_{i}}, \varepsilon_{a}, \varepsilon_{i}$ - dielectric permeability of the medium and particles.

Let us consider the particle's behavior of radius $a$ (fig. $5 b$ ) which is located at a distance $r$ from the electrode (at $r>>a$ ), the force acts on it that is determined by:

$$
\mathbf{F}=-\frac{3 \mathbf{E}^{2} a^{6} K^{2}}{8 r^{4}}
$$

and it is directed towards the rearest electrode. The forces $\mathbf{F}_{1}$ and $\mathbf{F}_{2}$ strive to minimize the energy of the system which leads to the change of particles' orientation and their clustering. In some proximity to the plane perpendicular to the electric field strength vector at $\theta=\operatorname{arctg} \sqrt{C}, \mathbf{F}_{2}$ - repulsion force, where $C$ - the concentration of contaminants in fuel.

The torque of the system, acting on a pair of particles, orients the system in such a way that the force of attraction arises between the particles, which increases as it turns to the angle $\theta$. The aggregates formed are most intensely attracted with the help of deposition. This makes it possible to determine the entire dispersed phase of the system in seconds or fractions of seconds with a sufficiently large initial concentration of particles.

An approximate expression to estimate the time of approach of two dispersed particles located in a liquid nonpolar medium at a distance from $r_{2}$ to $r_{1}$ can be determined from the expression

$$
t \cong \frac{2 \eta\left(r_{2 p r}^{5}-r_{1 p r}^{5}\right)}{5 \varepsilon_{0} \mathbf{E}^{2} K^{2}}
$$

or in case of the contact of particles’ surface

$$
t \cong \frac{2 \eta r_{2 p r}^{5}}{5 \varepsilon_{0} \mathbf{E}^{2} K^{2}}
$$

where: $\eta$ - dynamic viscosity of the medium, Pa·s; $\varepsilon_{0}$ - dielectric constant; $r_{1 p r}, r_{2 p r}$ - the distances corresponding to the initial and final position of particles, $r_{p r}=\frac{r}{2 a}, \mathrm{~m}$.

Having made the transformation of expression (6), if $r_{p r}=\frac{1}{\sqrt[3]{C}}$, we will obtain:

$$
\mathbf{E}_{\mathbf{K}}=\frac{1}{K} \sqrt{\frac{2}{5} \frac{\eta}{\varepsilon_{0} t^{3} \sqrt{C^{5}}}} .
$$


As we can see from this expression the value of the critical strength of an electric field $\mathbf{E}_{\mathbf{\kappa}}$ does not depend on the radius of particles but on their concentration $C$ only.

\section{Research Results and Discussion}

As a result of the mathematical analysis, using the Mathcad v15.0 software package, we obtained the dependence of the electric field strength $\mathbf{E}_{K}$ on the approach time $t$ of two dispersed particles located in a liquid nonpolar medium at a distance from $r_{2}$ to $r_{1}$ and the dynamic viscosity of diesel fuel $\eta$ at a concentration of particles $C$ in relative mass units.

Since the concentration of contaminating particles $C$ of diesel fuel does not exceed $10 \%$ of the mass, and the average fuel consumption of engines like 4Ч 110/125 and 4ЧН $110 / 125$ is $0.007 \mathrm{~kg} / \mathrm{s}$ [3], then in accordance with the graph (Fig. 6.) at a concentration of contaminating particles $C$ equal to $10 \%$ in a mass, the approach time t will be $0.75 \mathrm{~s}$ for a fuel whose dynamic viscosity $\eta$ is $3 \cdot 10^{3} \mathrm{~Pa} \cdot \mathrm{s}$, which will correspond to an electric field of $100 \mathrm{~V} / \mathrm{m}$.

The dynamic viscosity of fuel $\eta$ also has influence on the electric fiels strength $\mathbf{E}_{\kappa \mathbf{p}}$ when the viscosity grows $t$ increases and vice versa. The quality of cleaning is ensured under the condition, $0 \leq t \geq \frac{Q}{m}$ (Fig. 7), where: $Q$-fuel consumption, kg; $m$ - diesel fuel mass, $\mathrm{kg}$.

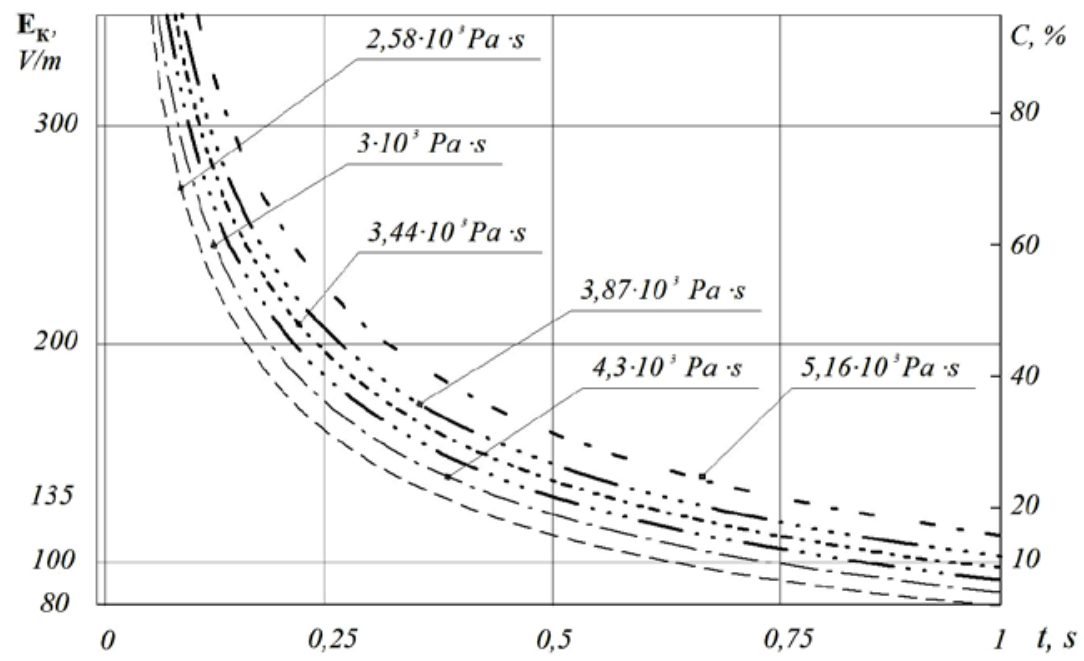

Fig. 6. The dependence graph of electric field strength $\mathbf{E} \boldsymbol{\kappa}$ versus time of approach of contaminating particles $t$ and their concentration $C$ 


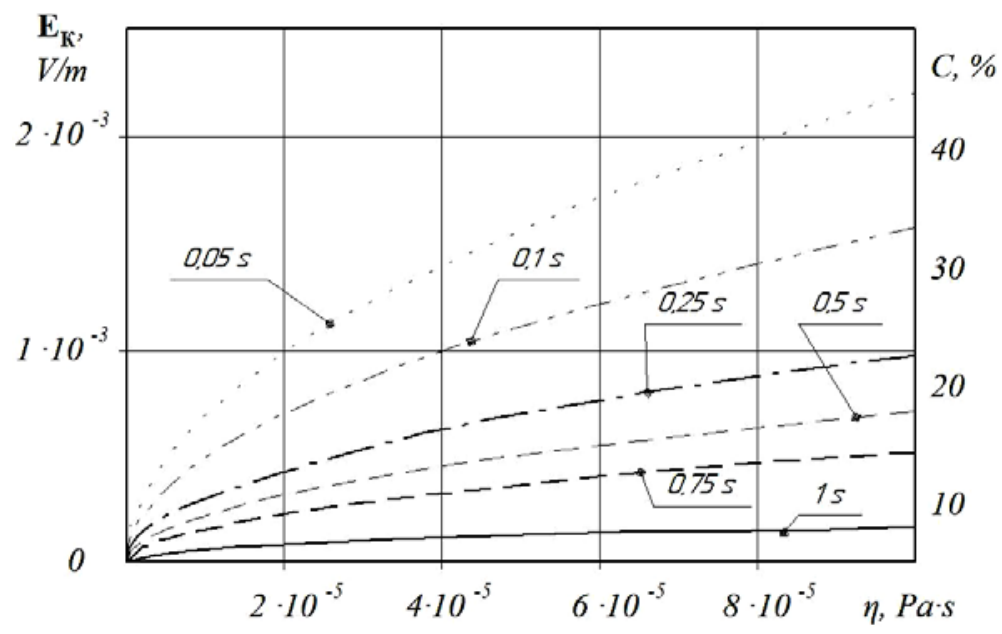

Fig 7. Dependence of the electric field strength $\mathbf{E}_{\boldsymbol{\kappa}}$ on the dynamic viscosity of diesel fuel $\eta$ and concentration $C$

When this condition is met, the cleaning efficiency depends on the speed and nature of the fuel flow, electric field strength, as well as on the area of active electrodes representing flat or curved plates $[4,6]$, which complicates and increases the cost of the design due to its high material consumption and dimensions. For the conditions of mobile vehicles, high cleaning efficiency and compactness are important; these conditions can be fulfilled using the coaxial arrangement of the electrodes.

Coaxial electrode systems in comparison with flat electrode systems have several advantages: firstly, their arrangement in the device is compact; secondly, they make it possible to obtain inhomogeneous electric fields with different inhomogeneity coefficients; thirdly, coaxial electrode systems do not create additional hydraulic resistance to fuel movement; moreover, these systems create symmetrical electric fields, which makes it possible to uniformly have an effect on the entire fuel volume.

\section{Conclusion}

The authors have considered the procedure of the cleaning process of diesel fuel in an electric field. A mathematical model of the electric cleaning process of diesel fuel in an electric field has been obtained and the boundaries of the initial parameters of the electric field have been determined.

\section{References}

1. Bulletin of tests of the northwest. Test materials of new agricultural equipment (Byulleten' ispytaniy Severo-Zapada. Testovyye materialy novoy sel'skokhozyaystvennoy tekhniki), FSBI North-West MIS, (2018)

2. Filimonova, O.N. Improvement of estimation parameters of fuel pumps of diesel engines for the certification of services on technical service. (Sovershenstvovaniye otsenochnykh parametrov toplivnykh nasosov dizel'nykh dvigateley pri sertifikatsii uslug po tekhnicheskomu servisu), KGAU-Kazan, (2005)

3. Report No. 03-63-18 of November 16, 2018. The quality of diesel fuel entering the region and used by agricultural enterprises (Otchet № 03-63-18 ot 16 noyabrya 2018 
goda. Kachestvo dizel'nogo topliva, postupayushchego $\mathrm{v}$ region i ispol'zuyemogo sel'skokhozyaystvennymi predpriyatiyami), FSBI «Vladimir State Zone MIS», (2018)

4. Kovalenko, V.P. Cleaning of oil products from contamination. (Ochistka nefteproduktov ot zagryazneniya), Nedra, (1990)

5. Lomonosov, D.A. Increase of durability plunging vapor diesel fuel equipment by controlling the moisture in the fuel system under operating conditions of the southern Far East.( Povysheniye dolgovechnosti plunazhernykh par dizel'noy toplivnoy apparatury za schet kontrolya vlagosoderzhaniya v toplivnoy sisteme v usloviyakh ekspluatatsii yuga Dal'nego Vostoka), Ussuriisk, (2006)

6. Granovsky,M.G. Lavrov,I.S. Smirnov,O.V. Electrical treatment of liquids. (Elektroobrabotka zhidkostey), Chemistry, (1976)

7. Device for fuel treatment and purification of internal combustion engines (Ustroystvo dlya obrabotki i ochistki topliva dvigateley vnutrennego sgoraniya): Pat. 2270355, Russian Federation, f02m27/04 / Varnakov V.V., Kozhevnikov A.P., Abramov A.E.; applicant and patentee of the FGOU VPO Ulyanovsk state agricultural Academy. No 2004115006/06; Appl. 17.05.2004; publ. 20.02.2006, Byul. No. pp. 5 - 4.

8. Abramov, A.E. The theoretical basis of the electric cleaning of diesel fuel on mobile power machines for agricultural purposes. (Teoreticheskoye obosnovaniye elektricheskoy ochistki dizel'nogo topliva na mobil'nykh energeticheskikh mashinakh sel'skokhozyaystvennogo naznacheniya) Scientific journal «Proceedings of the international scientific and technical conference energy Supply and energy saving in agriculture», Vol. 2, pp. 277-283. (2010) 